\title{
Cost-minimization analysis favours intravenous ferric carboxymaltose over ferric sucrose or oral iron as preoperative treatment in patients with colon cancer and iron deficiency anaemia
}

\author{
Xavier Calvet ${ }^{\mathrm{a}, \mathrm{b}, \mathrm{c}, *}$, Emili Gené ${ }^{\mathrm{b}, \mathrm{d}, \mathrm{e}}$, Miquel ÀngelRuíz ${ }^{\mathrm{f}}$, Ariadna Figuerola ${ }^{\mathrm{a}, \mathrm{b}}$, \\ Albert Villoria $^{\mathrm{a}, \mathrm{b}}$, Mercedes Cucala ${ }^{\mathrm{g}}$, Fermín Mearin ${ }^{\mathrm{h}}$, Salvadora Delgado ${ }^{\mathrm{i}}$ and \\ Jose Luis Calleja ${ }^{j}$ \\ ${ }^{a}$ Servei Aparell Digestiu, Corporació Sanitària Universitària Parc Taulí, Sabadell, Spain \\ ${ }^{\mathrm{b}}$ CIBERehd, Instituto de Salud Carlos III, Spain \\ ${ }^{c}$ Departament de Medicina, Universitat Autònoma de Barcelona, Barcelona, Spain \\ ${ }^{\mathrm{d}}$ Servei d'Urgències, Corporació Sanitària Universitària Parc Taulí, Sabadell, Barcelona, Spain \\ ${ }^{\mathrm{e}}$ Departament de Medicina, Universitat Internacional de Catalunya, Spain \\ ${ }^{\mathrm{f}}$ Departament de Comptabilitat Analítica, Corporació Sanitària i Universitària Parc Taulí, Sabadell, \\ Barcelona, Spain \\ ${ }^{\mathrm{g}}$ Medical Department, Vifor Pharma España, Barcelona, Spain \\ ${ }^{\mathrm{h}}$ Gastroenterology Department, Centro Médico Teknon, Barcelona, Spain \\ ${ }^{\mathrm{i}}$ Gastrointestinal Surgery Department, Hospital Clinic de Barcelona, Barcelona, Spain \\ ${ }^{\mathrm{j} G a s t r o e n t e r o l o g y}$ Department, Hospital Puerta de Hierro, Madrid, Spain
}

Received 6 July 2015

Accepted 16 August 2015

\begin{abstract}
.
BACKGROUND: Ferric Carboxymaltose (FCM), Iron Sucrose (IS) and Oral Iron (OI) are alternative treatments for preoperative anaemia.

OBJECTIVE: To compare the cost implications, using a cost-minimization analysis, of three alternatives: FCM vs. IS vs. OI for treating iron-deficient anaemia before surgery in patients with colon cancer.

METHODS: Data from 282 patients with colorectal cancer and anaemia were obtained from a previous study. One hundred and eleven received FCS, 16 IS and 155 OI. Costs of intravenous iron drugs were obtained from the Spanish Regulatory Agency. Direct and indirect costs were obtained from the analytical accounting unit of the Hospital. In the base case mean costs per patient were calculated. Sensitivity analysis and probabilistic Monte Carlo simulation were performed.
\end{abstract}

\footnotetext{
${ }^{*}$ Corresponding author: Xavier Calvet, Servei de Malalties Digestives, Hospital de Sabadell, Departament de Medicina, Universitat Autònoma de Barcelona, CIBEREHD - Instituto de Salud Carlos III, ParcTaulí, 1, 08208 Sabadell (Barcelona), Spain. Tel.: +34 937231010 (20111); Fax: +34 937160646; E-mail: xcalvet@tauli.cat.
} 
RESULTS: Total costs per patient were $1827^{\circledR}$ in the FCM group, $2312^{\circledR}$ in the IS group and $2101^{\circledR}$ in the OI group. Cost savings per patient for FCM treatment were $485^{\circledR}$ compared to IS and $274^{\circledR}$ compared to OI. A Monte Carlo simulation favoured the use of FCM in $84.7 \%$ and $84.4 \%$ of simulations when compared to IS and OI, respectively.

CONCLUSIONS: FCM infusion before surgery reduced costs in patients with colon cancer and iron-deficiency anaemia when compared with OI and IS.

Keywords. Cost-minimization analysis, ferric carboxymaltose, iron sucrose, iron deficiency, colorectal neoplasia

\section{Background}

Preoperative anaemia is extremely common in patients with colorectal cancer, with rates as high as $70 \%$ [1]. The most common cause of anaemia in colon cancer is the gastrointestinal blood loss that occurs in association with tumour ulceration and with malnutrition derived from the disease itself [1]. In addition, blood loss during surgery aggravates the anaemia.

Preoperative anaemia is emerging as a common and significant health problem [2]. It has been associated with increased postoperative morbidity and mortality, reduced quality of life, and longer hospitalization in many different settings [1-5]. Anaemia may contribute to complications both during and after surgery. In addition, a low preoperative haemoglobin concentration is one of the major risk factors for transfusion in surgery with moderate to high blood losses [12]. Perioperative transfusions may have an unfavourable effect on patient outcomes and increase the risk of infections and subsequent cancer recurrence [677]. Therefore, in the context of elective surgery, preoperative anaemia should be detected and evaluated as early to start a suitable treatment.

Oral iron (OI) administration is often not feasible or insufficient because intestinal absorption and digestive tolerance of iron salts are insufficient to timely recover anaemia before surgery [8]. By contrast, intravenous (i.v.) iron is usually well tolerated and allows administration of larger iron doses [9]. Many studies have shown that i.v. iron is more efficacious and better tolerated than oral iron supplementation [10-15].

In the past, iron dextran formulations carried a significant risk of anaphylaxis. For this reason, new formulations such as iron sucrose (IS) and, later, ferric carboxymaltose (FCM) have been developed [16]. These compounds have shown an excellent safety profile, and IS was the preferred drug in most hospitals until FCM became available. Although both compounds allow administration of much larger daily doses than their oral counterparts, FCM allows the administration of up to $1000 \mathrm{mg}$ of iron in a single infusion, while IS is restricted to a maximum of $200 \mathrm{mg}$ per day given not more than three times per week [17]. FCM has a higher price than other i.v. iron preparations, but the fact that a high dose can be administered in a single infusion may be a clear efficiency advantage: not only does it require fewer hospital visits and vein punctures [18]19] but also induces a better compliance allowing a quicker recovery of anemia, thus improving the preoperative status of the patient [19].

A recent cohort study [20] showed that FCM before surgery significantly improved haemoglobin levels, drastically reducing the number of perioperative transfusions and cutting the mean time of hospitalization after surgery by two days. The study also showed a trend towards fewer postoperative complications. Besides the clinical benefit, however, it is important to determine the comparative total costs of intravenous iron administration in order to determine whether iron infusion is cost-effective, and which infusion strategy is preferable.

The aim of this study was to compare the cost implications, using a cost-minimization analysis, of three strategies: i.v. FCM versus i.v. IS and OI treatment for treating iron-deficient anaemia before surgery in patients with colon cancer. 
Table 1

Costs and assumptions used in the analysis, including upper and lower bounds used in the sensitivity and Monte Carlo analysis. All personnel and indirect costs were obtained from the accounting department of the Hospital of Sabadell. Relevant clinical data were calculated from the data of individual patients. Bounds for clinical data were calculated by using \pm SD

\begin{tabular}{|c|c|c|c|}
\hline & Baseline & Lower bound & Upper bound \\
\hline \multicolumn{4}{|l|}{ Cost $(2013 €)$} \\
\hline Cost iron sucrose $200 \mathrm{mg}$ & 21 & 5 & 23 \\
\hline Cost ferric carboxymaltose $1000 \mathrm{mg}$ & 185 & 80 & 200 \\
\hline Cost infusion iron sucrose (1h $\left.15^{\prime}\right)$ & 40 & 35 & 60 \\
\hline Cost infusion ferric carboxymaltose (45') & 27 & 20 & 42 \\
\hline Cost per day of hospitalization & 188 & 150 & 400 \\
\hline Cost transfusion (per RBC* unit) & 110 & 80 & 200 \\
\hline \multicolumn{4}{|l|}{ Relevant clinical data } \\
\hline I.v. Iron, mean total dose FCM & 1275 & 845 & 1675 \\
\hline I.v. Iron, mean total dose IS & 756 & 514 & 998 \\
\hline Transfusion rate, OI (units/ patient) & 0.49 & 0 & 1.35 \\
\hline Transfusion rate, IS (units/ patient) & 0.63 & 0 & 1.65 \\
\hline Transfusion rate, FCM (units/patient) & 0.11 & 0 & 0.55 \\
\hline Hospitalization (days) OI & 10.9 & 7.4 & 14.4 \\
\hline Hospitalization (days) FCM & 8.3 & 5.7 & 10.9 \\
\hline Hospitalization (days) IS & 10.6 & 7.5 & 13.7 \\
\hline
\end{tabular}

${ }^{*}$ RBC: Red Blood Cell.

\section{Methods}

Individual data of patients with colon cancer and preoperative iron-deficient anaemia were retrieved from a previous cohort study. The series of patients has been described elsewhere [20]. In addition, the data from a small retrospective series of colon cancer patients treated with IS were also used for the present analysis. Costs of drugs were obtained from the prices approved by the Spanish Agency for the Regulation of Drugs and Healthcare Products [21]. Personnel costs, indirect costs and non-hospital direct costs for iron infusion were obtained from a previous study by our group [22], and the direct and indirect costs of a day of hospitalization and in-hospital transfusion were obtained from the accounting department of the Hospital of Sabadell, Spain using a full-cost model for assigning costs to each process. This model attributes all corresponding organizational costs to any process or product whose cost one intends to measure, including direct and indirect costs. Direct costs include the needs for medical material, personnel and diagnostic procedures. Indirect costs include the fraction of the common hospital costs imputable to a process, and cover (among other things) administrative costs, structural costs, and maintenance and cleaning services. The model divides the hospital activity into different processes and sub-processes and assigns to each one their corresponding direct and indirect costs. Costs obtained for other sources were used to confirm the accuracy of the data and to determine the limits for the sensitivity analysis [23 24]. Costs measured in Euros (€) for the year 2009 in the previous study were corrected by increasing it according to Retail Price Index (RPI) increases during the period 2009-2013. Costs were not discounted due to the short time frame of analysis. Major cost estimates are shown in Table 1.

A pharmaco-economic evaluation was performed from a Third-payer perspective, using cost minimization analysis. Cost-minimization is a tool used in pharmacoeconomics to compare multiple drugs of similar efficacy and safety. Base case total costs per patient were calculated using the individual patients' data for the three different groups: patients treated with FCM, IS, or OI. The primary outcome measure was the cost of the management of each patient from diagnosis to hospital discharge. This parameter was calculated by adding the three major components of cost that were expected to be relevant for the analysis: 1) the total cost of intravenous iron infusion (including costs of the drug and direct and 
indirect costs of outpatient infusion in a day-care unit) in the FCM and IS groups, 2) the costs of the transfusions needed, and 3) hospitalization costs. As the clinical characteristics of the patients in the IS, FCM and oral iron groups were not significantly different (Table 1), costs of surgery were assumed to be similar for the three groups. The complication rate did not differ significantly between groups. In addition, costs for each complication were extremely difficult to calculate. Finally, as complications prolong hospital stay, their cost was already included in the costs of a longer hospital stay. In consequence, to avoid considering their effect twice, costs of complications were not accounted for separately but were subsumed under the total costs of hospitalization. Calculations were performed using Microsoft Excel $\mathrm{XP}^{\mathrm{TM}}$.

One-way and two-way sensitivity analyses were performed by changing baseline estimates for costs within a range of potentially reasonable values and evaluating whether these changes modify the conclusions reached using baseline estimates for costs. As well as these evaluations, an additional sensitivity analysis was performed excluding outlier patients (defined empirically as those with a hospital length of stay over 20 days). Calculations were performed using Microsoft Excel XP ${ }^{\mathrm{TM}}$.

Finally, probabilistic sensitivity analysis was performed using Monte Carlo simulations for Microsoft Excel $\mathrm{XP}^{\mathrm{TM}}$. Monte Carlo simulations are a class of computational algorithms that rely on repeated random sampling to compute their results. The model assigns random values under a predetermined distribution to the variables shown to be most influential in the final results in the one and two-way analysis. Variables included in the analysis were cost of IS and FCM, total cost of iron infusion, cost of transfusion, cost of hospital stay, number of transfusions and days of hospitalization. These variables were tested both according to a normal distribution (number of transfusions and days of hospital stay) and a triangular distribution (for cost variables), and performing 10,000 iterations.

The Ethics Committee of the Hospital de Sabadell reviewed and approved the study. Individual data from the patients were processed anonymously and neither the investigators nor third parties had access to their personal data. Management of individual patients' data complied with the Spanish Personal Data Protection Act of 1999.

\section{Results and discussion}

\subsection{Results}

Data from patients receiving only oral iron $(n=155)$ or iron sucrose $(n=16)$ were collected retrospectively. Immediately afterwards, a cohort of 111 patients received FCM after the diagnosis of colon cancer and before surgery [20]. Apart from the iron infusion, all cohorts were managed in exactly the same way as the historical cohort. Table 2 shows the clinical characteristics, the number of patients, the mean total iron dose, the number of patients requiring transfusion and the mean number of transfusions required in each group.

Cost-minimization analysis showed that, under baseline costs and assumptions, FCM was less costly than IS or OI. Total costs per patient (including costs of iron infusion, transfusion and hospitalization) were $1827 €$ for FCM, 2312 for IS and $2101 €$ for OI. Therefore, baseline data cost savings for FCM treatment were $485 €$ when compared to IS and $274 €$ when compared to OI.

Table 3 shows the sensitivity analysis for the costs and assumptions evaluated in the analysis. The analysis shows that the most influential variable in the analysis was length of hospitalization. Figure 1 shows bivariate sensitivity analysis regarding length of hospitalization and costs. Baseline hospitalization reductions with FCM treatment were 2.3 days when compared to IS (blue dotted line) and 2.6 days when 
Table 2

Baseline, clinical and surgical characteristics of patients

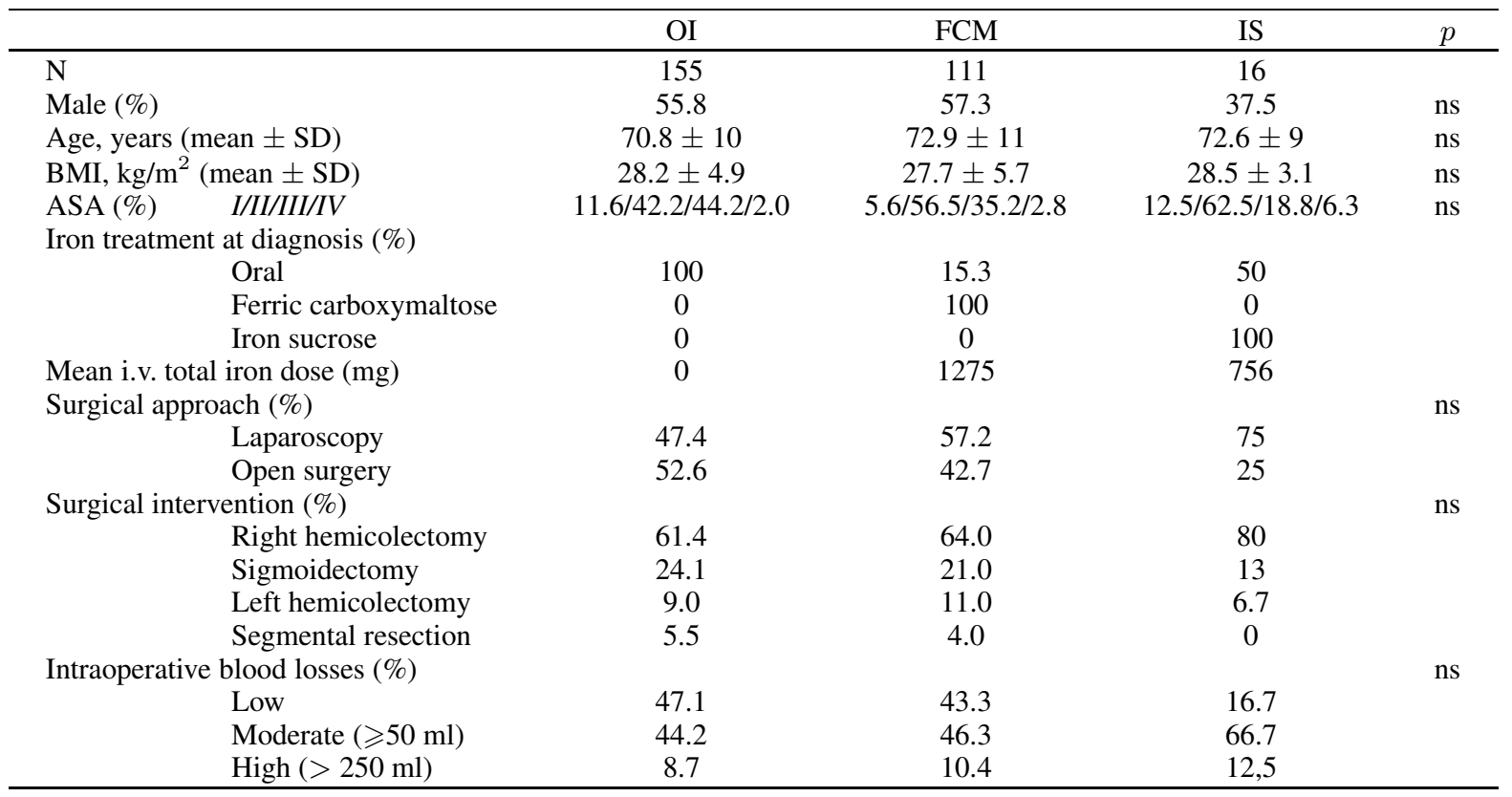

Table 3

Results of the sensitivity analysis

\begin{tabular}{|c|c|c|c|c|c|c|}
\hline \multirow[t]{2}{*}{ Total patients' cost (2013€) } & \multicolumn{2}{|c|}{ FCM } & \multicolumn{2}{|c|}{ IS } & \multicolumn{2}{|c|}{ OI } \\
\hline & Lower & Upper & Lower & Upper & Lower & Upper \\
\hline Cost i.v. iron & 1698 & 1851 & 2241 & 2318 & 2101 & 2101 \\
\hline Cost infusion & 1825 & 1847 & 2243 & 2383 & 2101 & 2101 \\
\hline Cost per day of hospitalization & 1517 & 3587 & 1899 & 4550 & 1690 & 4415 \\
\hline Cost transfusion (per RBC* unit) & 1828 & 1842 & 2222 & 2360 & 2089 & 2149 \\
\hline \multicolumn{7}{|l|}{ Clinical data } \\
\hline I.v. iron, mean total dose & 1752 & 1933 & 2237 & 2369 & 2101 & 2101 \\
\hline Transfusion rate, (units/patient) & 1820 & 1880 & 2234 & 2415 & 2050 & 2199 \\
\hline Hospitalization (days) & 1343 & 2324 & 1720 & 2886 & 1439 & 2762 \\
\hline
\end{tabular}

${ }^{*}$ RBC: Red blood cell.

compared to OI (red dotted line) resulting in respective cost savings of $485 €$ and $274 €$ (dotted circles). Blue solid line represents the incremental cost of IS depending on the hospitalization difference with regard to the FCM-treated group. IS would need to save 0.2 days or more (blue circle) when compared to FCM to achieve a costs saving. Red solid line shows that FCM treatment may result in cost savings if hospitalization days saved are 1.2 or more days (red circle) when compared to OI.

Exclusion of hospitalization outliers (patients admitted for longer than 20 days) reduced the differences between groups, although the analysis still favoured FCM. Total costs per patient were $1532 €$ in the FCM group, $1700 €$ in the IS group and $1693 €$ in the OI group.

The Monte Carlo simulation favoured the use of FCM over IS with a mean incremental cost of $578 €$ per patient. Figure 2 shows the Monte Carlo simulation after 10,000 iterations comparing FCM with IS. In a), the bars show the number of iterations that resulted in a given incremental cost value in $€$. Values under 0 correspond to the simulations that favour the use of iron sucrose. As shown by the figure, the model favoured the use of ferric carboxymaltose in $84.7 \%$ of the iterations. Part b) shows the cumulative 


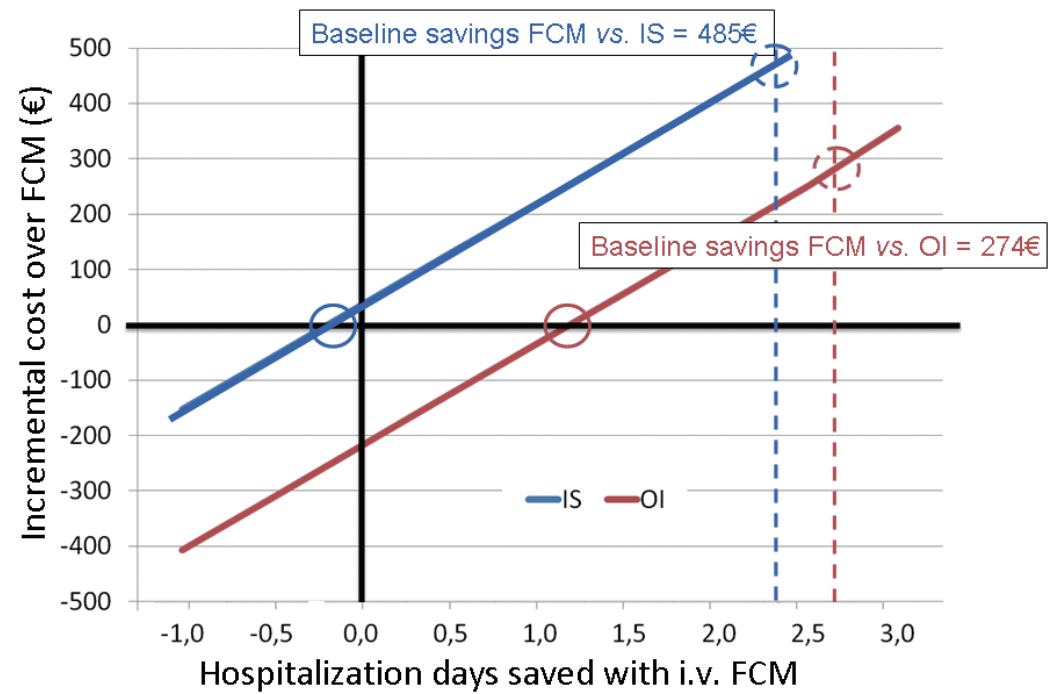

Fig. 1. Two-way sensitivity analysis showing the effect of hospitalization in total cost for patient. (Colours are visible in the online version of the article; http://dx.doi.org/10.3233/THC-151074)

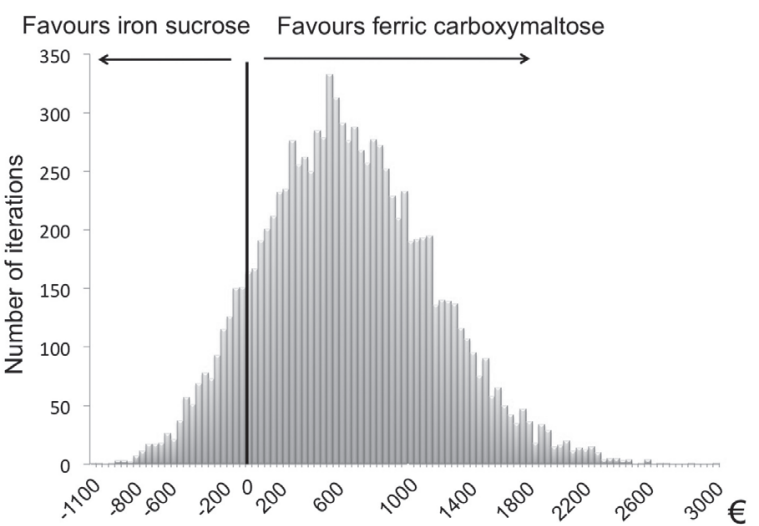

(a)

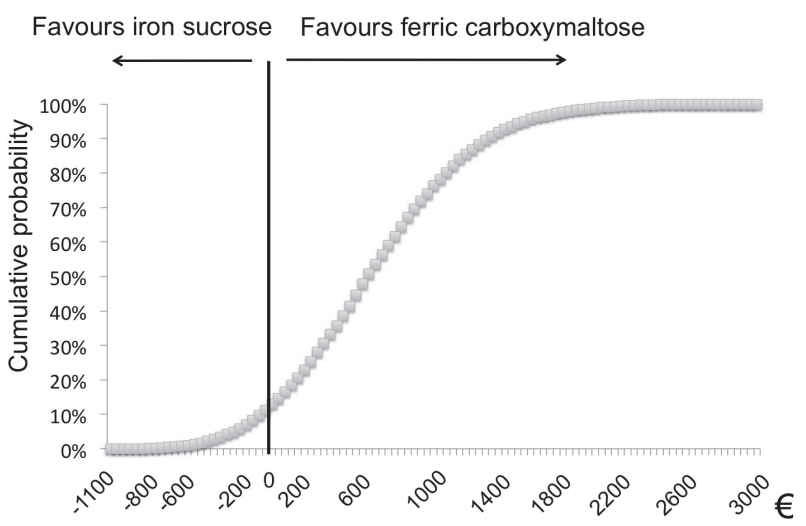

(b)

Fig. 2. Monte Carlo simulation after 10,000 iterations comparing ferric carboxymaltose (FCM) with iron sucrose (IS). a) The bars show the number of iterations that resulted in a given incremental cost value. Values under 0 correspond to the simulations that favour the use of iron sucrose. As shown by the figure, the model favoured the use of ferric carboxymaltose in $84.7 \%$ of the iterations. b) Cumulative probability for each incremental cost value.

probability for each incremental cost value.

Similarly, Monte Carlo simulation favoured the use of FCM over OI with a mean incremental cost of $641.3 €$ per patient. Figure 3 shows the Monte Carlo simulation after 10,000 iterations comparing ferric carboxymaltose (FCM) with oral iron treatment (OI). In part a), the bars show the number of iterations that resulted in a given incremental cost value in $€$. Values under 0 correspond to the simulations that favour the use of oral iron treatment. The model favoured the use of ferric carboxymaltose in $84.4 \%$ of the iterations. Part b) shows the cumulative probability for each incremental cost value. 


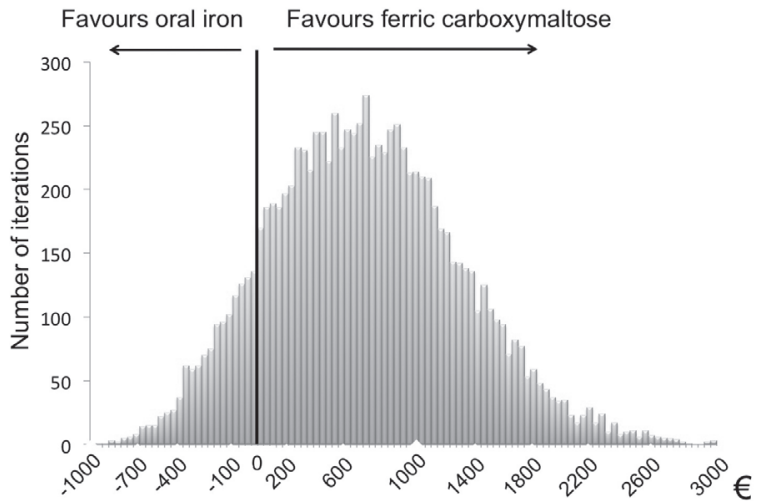

(a)

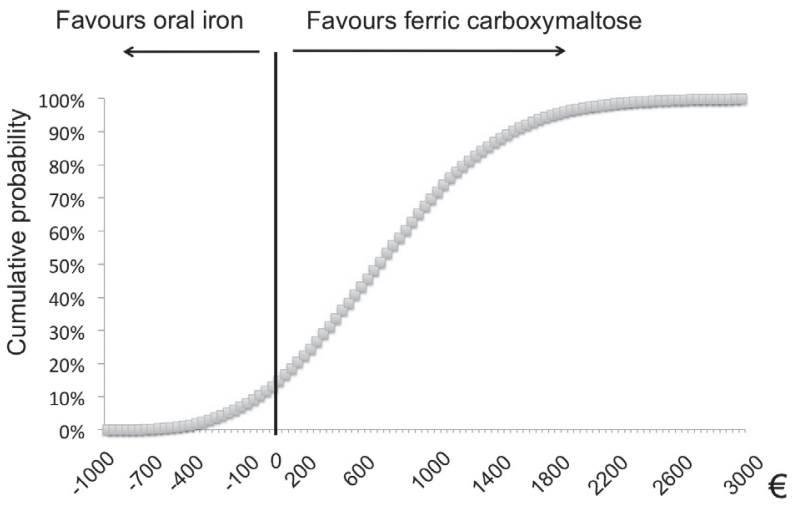

(b)

Fig. 3. Monte Carlo simulation after 10,000 iterations comparing ferric carboxymaltose (FCM) with oral iron treatment (OI). a) The bars show the number of iterations that resulted in a given incremental cost value. Values under 0 correspond to the simulations that favour the use of oral iron treatment. As shown by the figure, the model favoured the use of ferric carboxymaltose in $84.4 \%$ of the iterations. b) Cumulative probability for each incremental cost value.

\subsection{Discussion}

The present cost-minimization analysis evaluates the comparative cost of using either IS, OI or FCM for treating iron deficiency anaemia in colon cancer patients undergoing surgery. The study suggests that under standard conditions the savings in costs offset the higher drug cost of FCM compared with IS or OI. The results of the analysis were fairly stable and were reproduced in most of the univariate and multivariate sensitivity analyses performed. The analysis also showed that this economic benefit relies heavily on the reduction of hospital stay due to a better control of the anaemia and, possibly, to the lower rate of complications. It is worth noting that these conclusions were obtained using the Spanish National Health System hospitalization and personnel costs, which are particularly low compared to those in other Western countries. So in fact, the benefit of FCM i.v. treatment may be larger in other settings - for example, in the US, where hospitalization costs may surpass those in Spain by a factor of 5 to 15 per inpatient day [25]. In this case, even with minimal reductions in hospital stay, FCM treatment may result in cost savings.

The analysis is based on iron doses administered to real patients. This is both a strength and a limitation of the study. It is a strength because the estimated costs will probably reflect the current situation in clinical practice. It can be seen as a limitation because the analysis was performed in a specific patient population [20], and in another setting the costs might have been different. However, the sensitivity analysis of the study suggests that the higher the hospitalization costs, the more FCM is favoured.

A second limitation is that the analysis assumes equal clinical outcomes and safety for all cohorts in the study. Although it is true that there was a trend towards a lower complication rate with FCM, the differences between groups did not achieve significance. We believed that it was methodologically sounder to assume that differences were due to chance, in order to avoid biasing the study towards FCM treatment. For this reason we did not take complications into account in the analysis, and this may have introduced a slight bias in favour of the IS and OI groups. In fact, as complications tend to increase hospitalization, the study indirectly takes this parameter into account.

A final limitation of the analysis is that its scope is limited to direct and indirect hospital costs. Measuring and adding direct non-hospital costs - for example, work days lost by the patient or their relatives, 
or the cost of transportation to the hospital - would have probably increased the estimated benefits of FCM.

Regarding FCM safety, studies and reviews have not found any association with increased risk [17, 19[26-30]. A recent study in patients with heart failure and iron deficiency showed an improvement in functional capacity and even found an improvement in quality of life along with a trend towards fewer hospitalization rate for any cardiovascular cause or death in patients treated with FCM [30].

Finally, our study confirms that administration of larger doses of iron in a smaller number of infusions reduces costs. In the setting analysed, IS was more expensive due to the cost of repeated infusions. In addition, the total iron dose achieved with IS was lower and not related to a clear reduction in the need for transfusion or the length of hospitalization.

\section{Conclusions}

In conclusion, in this pharmaco-economic model, preoperative ferric carboxymaltose infusion was less costly than iron sucrose infusion or oral iron replacement and appeared to reduce the total costs in patients with iron-deficient anaemia and colon cancer.

\section{Acknowledgements}

We are indebted to Michael Maudsley for his help with the English, and to Silvia Rodriguez Cerrillo for her help in managing all study data.

\section{Conflict of interest}

Xavier Calvet: Research grants, Advisory and eductional activities for Vifor Pharma. Fermin Mearin: Advisory and lectures for Vifor Pharma. Salvadora Delgado: Advisory and speaker for Vifor Pharma Mercedes Cucala: Vifor Pharma employee. There are no non-financial competing interests to declare in relation to this manuscript.

\section{References}

[1] Musallam KM, Tamim HM, Richards T, Spahn DR, Rosendaal FR, Habbal A, et al. Preoperative anaemia and postoperative outcomes in non-cardiac surgery: A retrospective cohort study. Lancet 2011; 378(9800): 1396-407. Epub 2011/10/11.

[2] Beattie WS, Karkouti K, Wijeysundera DN, Tait G. Risk associated with preoperative anemia in noncardiac surgery: A single-center cohort study. Anesthesiology 2009; 110(3): 574-81. Epub 2009/02/13.

[3] Myers E, O'Grady P, Dolan AM. The influence of preclinical anaemia on outcome following total hip replacement. Archives of Orthopaedic and Trauma Surgery 2004; 124(10): 699-701. Epub 2004/11/02.

[4] Leichtle SW, Mouawad NJ, Lampman R, Singal B, Cleary RK. Does preoperative anemia adversely affect colon and rectal surgery outcomes? Journal of the American College of Surgeons 2011; 212(2): 187-94. Epub 2011/02/01.

[5] Cladellas M, Bruguera J, Comin J, Vila J, de Jaime E, Marti J, et al. Is pre-operative anaemia a risk marker for in-hospital mortality and morbidity after valve replacement? European Heart Journal 2006; 27(9): 1093-9. Epub 2006/03/16.

[6] Amato AC, Pescatori M. Effect of perioperative blood transfusions on recurrence of colorectal cancer: Meta-analysis stratified on risk factors. Diseases of the Colon and Rectum 1998; 41(5): 570-85. Epub 1998/05/21.

[7] Acheson AG, Brookes MJ, Spahn DR. Effects of allogeneic red blood cell transfusions on clinical outcomes in patients undergoing colorectal cancer surgery: A systematic review and meta-analysis. Annals of Surgery 2012; 256(2): 235-44. Epub 2012/07/14. 
[8] Shander A, Knight K, Thurer R, Adamson J, Spence R. Prevalence and outcomes of anemia in surgery: A systematic review of the literature. The American Journal of Medicine 2004; 116 Suppl 7A: 58S-69S. Epub 2004/03/31.

[9] Gisbert JP, Gomollon F. Common misconceptions in the diagnosis and management of anemia in inflammatory bowel disease. The American Journal of Gastroenterology 2008; 103(5): 1299-307. Epub 2008/05/15.

[10] Johnson DW, Herzig KA, Gissane R, Campbell SB, Hawley CM, Isbel NM. A prospective crossover trial comparing intermittent intravenous and continuous oral iron supplements in peritoneal dialysis patients. Nephrology, dialysis, transplantation: Official publication of the European Dialysis and Transplant Association - European Renal Association 2001; 16(9): 1879-84. Epub 2001/08/28.

[11] Kim YH, Chung HH, Kang SB, Kim SC, Kim YT. Safety and usefulness of intravenous iron sucrose in the management of preoperative anemia in patients with menorrhagia: A phase IV, open-label, prospective, randomized study. Acta Haematologica 2009, 121(1): 37-41. Epub 2009/04/01.

[12] Seid MH, Derman RJ, Baker JB, Banach W, Goldberg C, Rogers R. Ferric carboxymaltose injection in the treatment of postpartum iron deficiency anemia: A randomized controlled clinical trial. American Journal of Obstetrics and Gynecology 2008; 199(4): 435 e1-7. Epub 2008/10/22.

[13] Littlewood TJ, Alikhan R. The use of intravenous iron in patients with cancer-related anaemia. British Journal of Haematology 2008; 141(6): 751-6. Epub 2008/04/16.

[14] Lindgren S, Wikman O, Befrits R, Blom H, Eriksson A, Granno C, et al. Intravenous iron sucrose is superior to oral iron sulphate for correcting anaemia and restoring iron stores in IBD patients: A randomized, controlled, evaluator-blind, multicentre study. Scandinavian Journal of Gastroenterology 2009; 44(7): 838-45. Epub 2009/03/31.

[15] Kulnigg S, Stoinov S, Simanenkov V, Dudar LV, Karnafel W, Garcia LC, et al. A novel intravenous iron formulation for treatment of anemia in inflammatory bowel disease: the ferric carboxymaltose (FERINJECT) randomized controlled trial. The American Journal of Gastroenterology 2008; 103(5): 1182-92. Epub 2008/03/29.

[16] Hayat A. Safety issues with intravenous iron products in the management of anemia in chronic kidney disease. Clinical Medicine \& Research 2008; 6(3-4): 93-102. Epub 2009/03/28.

[17] Muñoz M, Gomez-Ramirez S, Garcia-Erce JA.) Intravenous iron in inflammatory bowel disease. World Journal of Gastroenterology : WJG 2009; 15(37): 4666-74. Epub 2009/09/30.

[18] Rubio C. Análisis farmacoeconómico del tratamiento de la deficiencia de hierro con hierro carboximaltosa $\left(\right.$ Ferinject ${ }^{\circledR}$ ) en España. PharmacoEconomics-Spanish Research Articles 2010; 7(3): 109-117.

[19] Evstatiev R, Marteau P, Iqbal T, Khalif IL, Stein J, Bokemeyer B, et al. FERGIcor, a randomized controlled trial on ferric carboxymaltose for iron deficiency anemia in inflammatory bowel disease. Gastroenterology 2011; 141(3): 846-53 e1-2. Epub 2011/06/28.

[20] Delgado S, Calleja JL, del Val A, Hervas AJ, Molina JL, Larraona JL, et al. Efficacy of Preoperative Administration of Ferric Carboxymaltose in Colon Cancer Patients and Anemia. Gastroenterology 2013; 144(5) Suppl 1: S-581.

[21] Consejo General de Colegios Oficiales de Farmacéuticos website. [cited 2013 September 2013]; Available from: https:// botplusweb.portalfarma.com/.

[22] Calvet X, Ruiz MA, Dosal A, Moreno L, Lopez M, Figuerola A, et al. Cost-minimization analysis favours intravenous ferric carboxymaltose over ferric sucrose for the ambulatory treatment of severe iron deficiency. PloS One 2012; 7(9): e45604. Epub 2012/10/03.

[23] CVE-2012-17728 Aprobación de la tarifa de precios de los productos y servicios que suministra el Banco de Sangre y Tejidos de Cantabria para el 2013, Boletin Oficial de Cantabria,1 de Enero 2013 [Internet]. March 2013: [161 p.]. Available from: http://boc.cantabria.es.

[24] ORDRE SLT/106/2013, de 24 de maig, per la qual es determinen per a l'any 2013 els preus unitaris i la restade valors a què es refereix l'article 5 del Decret 170/2010, de 16 de novembre, de regulació del sistema de pagament de serveis sanitaris en l'àmbit del Servei Català de la Salut. Diari Oficial de la Generalitat de Catalunya [Internet]. June 2013; (6387). Available from: http://www.gencat.cat/dogc.

[25] Oh J. Average Cost Per Inpatient Day Across 50 States in 2010. Becker's Hospital Reeview [Internet]. 2011 November 2013. Available from: http://www.beckershospitalreview.com/lists/average-cost-per-inpatient-day-across-50-statesin-2010.html.

[26] Qunibi WY. The efficacy and safety of current intravenous iron preparations for the management of iron-deficiency anaemia: A review. Arzneimittel-Forschung 2010; 60(6a): 399-412. Epub 2010/07/23.

[27] Kociol RD, Newby LK. Ferric carboxymaltose improved symptoms and quality of life in patients with chronic heart failure and iron deficiency. Annals of Internal Medicine 2010; 152(8): JC4-5. Epub 2010/04/21.

[28] Covic A, Mircescu G. The safety and efficacy of intravenous ferric carboxymaltose in anaemic patients undergoing haemodialysis: A multi-centre, open-label, clinical study. Nephrology, dialysis, transplantation: Official publication of the European Dialysis and Transplant Association - European Renal Association 2010; 25(8): 2722-30. Epub 2010/03/02.

[29] Grimmelt AC, Cohen CD, Fehr T, Serra AL, Wuethrich RP. Safety and tolerability of ferric carboxymaltose (FCM) 
for treatment of iron deficiency in patients with chronic kidney disease and in kidney transplant recipients. Clinical Nephrology 2009; 71(2): 125-9. Epub 2009/02/11.

[30] Anker SD, Comin Colet J, Filippatos G, Willenheimer R, Dickstein K, Drexler H, et al. Ferric carboxymaltose in patients with heart failure and iron deficiency. The New England Journal of Medicine 2009; 361(25): 2436-48. Epub 2009/11/19. 